\title{
New manganese-based catalyst systems for alkyd paint drying
}

\author{
Zhiliang Liu ${ }^{\text {a }}$, Huub Kooijman ${ }^{b}$, Anthony L. Spek ${ }^{b}$, Elisabeth Bouwman ${ }^{\mathrm{a}, *}$ \\ ${ }^{a}$ Leiden Institute of Chemistry, Gorlaeus Laboratories, Leiden University, P.O. Box 9502, 2300 RA Leiden, The Netherlands \\ ${ }^{\mathrm{b}}$ Bijvoet Center for Biomolecular Research, Crystal and Structural Chemistry, Utrecht University, \\ Padualaan 8, 3584 CH Utrecht, The Netherlands \\ Received 18 April 2007; accepted 2 August 2007
}

\begin{abstract}
The autoxidation and oligomerisation of ethyl linoleate (EL) catalyzed by manganese salts in combination with several Schiff-base ligands has been studied making use of time-resolved FT-IR spectroscopy. The results indicate that several of the combinations exhibit relatively high catalytic activity for the autoxidation of EL. One of the catalyst systems was studied in more detail. The reaction between $\mathrm{MnCl}_{2} \cdot 2 \mathrm{H}_{2} \mathrm{O}$ and the Schiff-base ligand (L4) formed by the condensation of 2-pyridinealdehyde and 2-aminopyridine has been studied to clarify the catalytic reaction process. It was found that the Schiff-base ligand L4 reacts with water and the tridentate ligand (2-pyridyl)(2-pyridylamino)methanol (HOL4) is formed. A single crystal structure of $\left[\mathrm{Mn}^{\mathrm{III}}(\mathrm{OL} 4)_{2}\right] \mathrm{Cl} \cdot 3 \mathrm{H}_{2} \mathrm{O}$ has been determined by X-ray diffraction methods.
\end{abstract}

(C) 2007 Elsevier B.V. All rights reserved.

Keywords: Ethyl linoleate; Manganese salts; Schiff-base ligands; Autoxidation; Catalysts

\section{Introduction}

The drying of paints containing unsaturated fatty acids such as alkyd resins, taking place through an oxidative polymerization of the carbon-carbon double bond, is a subject of intense academic and technological interest [1-5]. The drying process is a complex succession and superposition of numerous reactions. In this process, the alkyd resin binder molecules in the paint react with dioxygen; the decomposition of the alkyl hydroperoxides followed by radical recombination reactions results in the formation of a cross-linked network which thus cures the paints or coatings. Binder molecules typically are polyesters containing fatty acid side chains. The autoxidation of these fatty-acid side chains can be regarded as a lipid peroxidation process, resulting in hydroperoxide species (ROOH) [6]. Metal-based catalysts are usually necessary to decompose these hydroperoxides into alkoxy and peroxy radicals according to the well-known Haber-Weiss mechanism [7,8]. These radicals can then recombine to form ether, peroxo, and, to a lesser extent, carbon-carbon bonds. In Scheme 1, the course of the drying reactions is schematically shown.

\footnotetext{
* Corresponding author. Tel.: +31 71 5274550; fax: +31 715274451

E-mail address: bouwman@chem.leidenuniv.nl (E. Bouwman).
}

Cobalt complexes are the most widely used drying catalysts for oxidative air-drying alkyd paints. However, several reports have been published describing the possible carcinogenicity of cobalt salts and cobalt complexes $[9,10]$. Some commercial paint formulations contain manganese carboxylate as primary drier instead of cobalt, however, these do not have the same performance as cobalt $[7,11,12]$. This has initiated a search to find alternatives for cobalt complexes as drying catalysts in alkyd paint $[2,11-14]$. Recently, our group reported the manganesebased catalyst system $\left[\mathrm{Mn}(\mathrm{acac})_{3}\right] / \mathrm{bpy}$ (bpy $=2,2^{\prime}$-bipyridine), which exhibits a very high activity in the oxidation of unsaturated fatty acids [13]. Unfortunately, $\left[\mathrm{Mn}(\mathrm{acac})_{3}\right]$ is darkly colored precluding its application in commercial paint products. However, this research result stimulates further research to find new active manganese-based drying catalyst systems.

Because of the complex nature of real alkyd mixtures, a model reaction has been developed using ethyl linoleate (EL) as a substrate for rapid screening of new possible catalysts; the different activities can be compared using time resolved FT-IR and size exclusion chromatography $[11,12]$. Herein, we report the use of manganese salts in combination selected Schiff-base ligands (L1-L4, Scheme 2) as catalysts in the model oxidation reaction of EL. Time resolved FT-IR spectroscopy and size exclusion chromatography were used to study the catalytic activity. The reaction of $\mathrm{MnCl}_{2} \cdot 2 \mathrm{H}_{2} \mathrm{O}$ with the ligand $\mathrm{L} 4$ has been studied in detail to clarify the catalytic reaction process. 


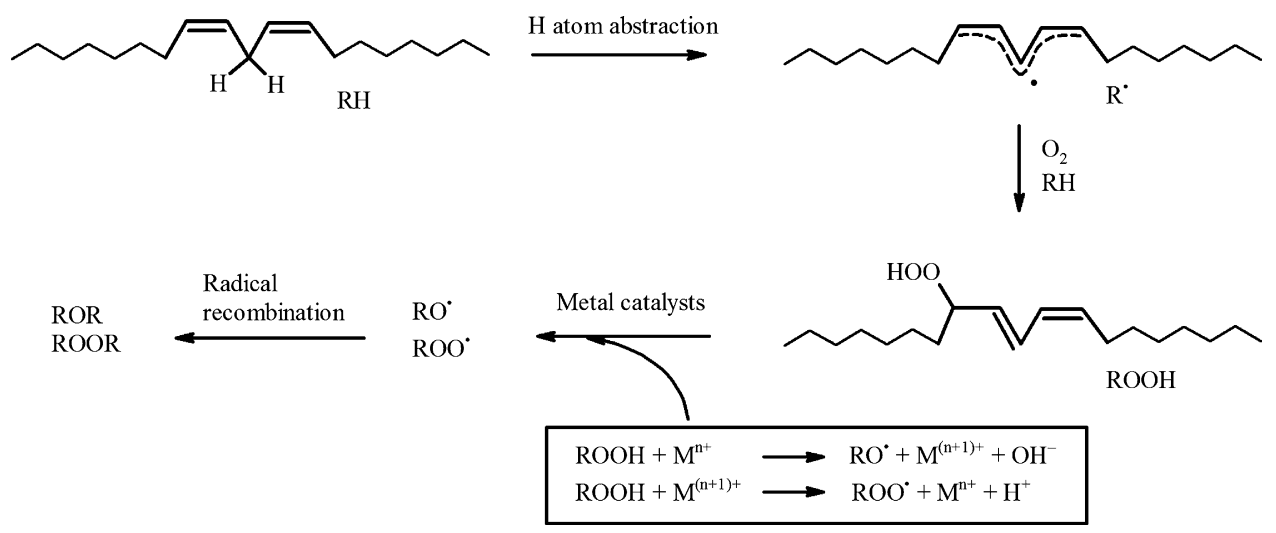

Scheme 1. Schematic impression of the autoxidation of fatty-acid side chains in alkyd resins.

\section{Experimental}

\subsection{Materials}

Technical ethyl linoleate (EL, 70\%; remainder ethyl oleate, ethyl palmitate and ethyl stearate [12]) was obtained from Fluka. The small amounts of hydroperoxides that are present in the EL were removed by passing the oil through a basic alumina column immediately before use. Other chemicals were all of reagent grade and were used as received.

\subsection{Synthesis of the ligands}

Standard solutions of the Schiff-base ligands L1-L4 were prepared by mixing proper amounts of 2-pyridinecarboxaldehyde with the appropriate amine in methanol, making $0.2 \mathrm{M}$ concentrations. For the FT-IR experiments these methanolic solutions were used as such, without isolation of the ligands.

\subsection{Synthesis of $\left[\mathrm{Mn}^{I I I}(\mathrm{OL} 4)_{2}\right] \mathrm{Cl} \cdot 3 \mathrm{H}_{2} \mathrm{O}$}

A methanol solution $(20 \mathrm{ml})$ containing $\mathrm{MnCl}_{2} \cdot 2 \mathrm{H}_{2} \mathrm{O}(0.8 \mathrm{~g}$, $5 \mathrm{mmol}$ ) was added to a mixture of 2-pyridinecarboxaldehyde $(1.07 \mathrm{~g}, 10 \mathrm{mmol})$ and 2-aminopyridine $(0.94 \mathrm{~g}, 10 \mathrm{mmol})$ dissolved in $10 \mathrm{ml}$ ethanol. The mixture was stirred for $3 \mathrm{~h}$ in an air-exposed condition and the color of the reaction mixture changed into brown-red. Several days later, well-shaped red crystals were obtained from the solution. IR $\left(\mathrm{cm}^{-1}\right): 3370$, 1615, 1601, 1504, 1485, 1314, 1274, 1055, 1039, 1027, 1010, 995, 760. Anal. calcd. for $\mathrm{C}_{22} \mathrm{H}_{26} \mathrm{ClMnN}_{6} \mathrm{O}_{5}$ : C, 48.45; H, 4.77; N, 15.42; Found: C, 48.67; H, 4.75; N, 15.38\%. ESI-MS: the parent peak $\left[\mathrm{Mn}(\mathrm{OL} 4)_{2}\right]^{+}$was observed at $\mathrm{m} / z=455.14$.

\subsection{Synthesis of $\left[\mathrm{Mn}^{I I}(\mathrm{L4}) \mathrm{Cl}_{2}\right] \cdot \mathrm{CH}_{3} \mathrm{OH}$}

A methanol solution (5 ml) containing $\mathrm{MnCl}_{2} \cdot 2 \mathrm{H}_{2} \mathrm{O}(0.8 \mathrm{~g}$, $5 \mathrm{mmol}$ ) was added to a mixture of 2-pyridinecarboxaldehyde $(1.07 \mathrm{~g}, 10 \mathrm{mmol})$ and 2-aminopyridine $(0.94 \mathrm{~g}, 10 \mathrm{mmol}) \mathrm{dis}-$ solved in $50 \mathrm{ml}$ acetonitrile. Argon was passed through the solution for $1.5 \mathrm{~h}$ and the reaction vessel with the yellow-orange solution was closed to air. Several days later, the paleyellow manganese(II) compound $\mathrm{Mn}^{\mathrm{II}}(\mathrm{L} 4) \mathrm{Cl}_{2}$ was obtained from the solution. IR $\left(\mathrm{cm}^{-1}\right)$ : $3325,1613,1576,1518,1488$, 1443, 1422, 1357, 1322, 1298, 1158, 1085, 1048, 1019, 996, 780, 756, 725, 635, 561, 494, 415. Anal. calcd. for $\mathrm{C}_{12} \mathrm{H}_{13} \mathrm{Cl}_{2} \mathrm{MnN}_{3} \mathrm{O}$ : C, 42.26; H, 3.84; N, 12.32; Found: C, $42.14 ; \mathrm{H}, 3.90 ; \mathrm{N}, 12.29 \%$. Upon longer standing and the slightest exposure to air the oxidized product $\left[\mathrm{Mn}(\mathrm{OL} 4)_{2}\right] \mathrm{Cl} \cdot 3 \mathrm{H}_{2} \mathrm{O}$ is obtained.

\subsection{Analytical methods}

C, $\mathrm{H}, \mathrm{N}$ determinations were performed on a Perkin-Elmer 2400 Series II elemental analyzer. FT-IR spectra were obtained on a Perkin-Elmer Paragon 1000 FT-IR spectrophotometer equipped with a Golden Gate ATR device, using the diffuse reflectance technique $\left(4000-400 \mathrm{~cm}^{-1}\right.$, resolution $\left.4 \mathrm{~cm}^{-1}\right)$. Electrospray mass spectra (ESI-MS) in $\mathrm{MeOH}$ solution were recorded on a Thermo Finnigan AQA apparatus.

Time-resolved FT-IR spectra were obtained on a Bio-RAD FTS-60A spectrometer equipped with a Specac ATR device (ZnSe crystal, angle of incidence 45 ) as the sample holder, using the reflectance technique $\left(4000-400 \mathrm{~cm}^{-1}\right.$, resolution $\left.2 \mathrm{~cm}^{-1}\right)$. For the time-resolved measurements the kinetic mode of the software Win IR pro has been used. Every 5 min an absorption spectrum was automatically recorded. After measurement

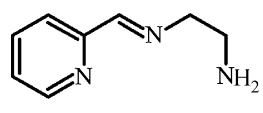

L1<smiles>NCCC/N=C/c1ccccn1</smiles>

L2

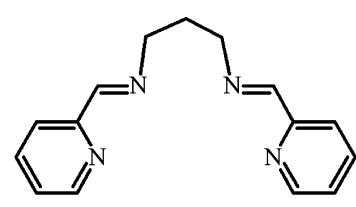

L3<smiles>C(=N/c1ccccn1)\c1ccccn1</smiles>

L4

Scheme 2. Schiff-base ligands used in this study. 
in the range of interest a baseline correction was performed and the peak at $3010 \mathrm{~cm}^{-1}$ (between 2992 and $3025 \mathrm{~cm}^{-1}$ ) was integrated. As output of this processing a file containing the integral of this peak at different times was obtained. The rate of the consumption of EL can be followed by plotting the natural logarithm of the percentage decrease of the peak integral of the $3010 \mathrm{~cm}^{-1}$ peak (between 2992 and $3025 \mathrm{~cm}^{-1}$ ) in the FT-IR spectrum, as was described by Vandevoort et al. [15]. In a typical oxidative cross-linking experiment, $500 \mu \mathrm{l}(1.0 \mathrm{mmol})$ of EL $(70 \%)$ was mixed with approximately $130 \mu$ l of the manganese salt dissolved in methanol $(0.02 \mathrm{M})$ and $26 \mu \mathrm{l}$ of the Schiff-base ligand (L) dissolved in methanol (0.2 M), resulting in a molar ratio of $\mathrm{EL} / \mathrm{Mn} / \mathrm{L} \approx 375 / 1 / 2$. Then $160 \mu$ l of the mixture was spread in a thin layer on the sample holder (resulting in approximately $0.3 \mathrm{~mm}$ layer thickness) to undergo time-resolved infrared measurements. This layer thickness was chosen to prevent the limitation of dioxygen diffusion from influencing the result [11].

Size-exclusion chromatography (SEC) measurements were performed in chloroform on two PL-gel Mixed-E columns $(300 \mathrm{~mm} \times 7.5 \mathrm{~mm}$ i.d. Polymer Laboratories) and an interferometric refractive index detector (Optilab DSP, Wyatt Technology) as concentration detector. The flow-rate was $1.0 \mathrm{ml} \mathrm{min}{ }^{-1}$ and the sample load was $100 \mu \mathrm{l}$ of the sample diluted in chloroform. The oxidation reactions to be analyzed with SEC were carried out in custom-made wells on a glass plate $(0.3 \mathrm{~mm}$ in depth and $2 \mathrm{~cm}$ in diameter $)$, to ensure reproducible film thickness. Two wells were each filled with $90 \mu \mathrm{l}$ of the reaction mixture prepared as described under FT-IR (see above). For each time interval a sample of $10 \mu \mathrm{l}$ was taken from a separate well and the sample was diluted in $1.0 \mathrm{ml}$ of chloroform to be subjected to SEC.

\subsection{X-ray data collection and structural determination}

Single crystals of the complex $\left[\mathrm{Mn}(\mathrm{OL} 4)_{2}\right] \mathrm{Cl} \cdot 3 \mathrm{H}_{2} \mathrm{O}$ were selected and mounted on a Nonius KappaCCD diffractometer with graphite-monochromated Mo-K $\alpha$ radiation $(\lambda=0.71073 \AA)$. Correction for absorption was considered not necessary. The structure was solved with Patterson methods and subsequent difference Fourier methods (DIRDIF) [16]. The structure refinement was done with SHELXL97 [17] against $F^{2}$ of all reflections. The co-ordinates of the amine and water hydrogen atoms were refined; all other hydrogen atoms were placed at calculated positions riding on their carrier atoms. Mild equal-distance restraints were applied to the $\mathrm{O}-\mathrm{H}$ and $\mathrm{H}-\mathrm{O}-\mathrm{H}$ distances of the water molecules. Molecular illustration, checking for higher symmetry and geometry calculations were performed with the PLATON package [18]. Crystallographic data: $\mathrm{C}_{22} \mathrm{H}_{20} \mathrm{MnN}_{6} \mathrm{O}_{2} \cdot \mathrm{Cl} \cdot 3 \mathrm{H}_{2} \mathrm{O}, M_{\mathrm{r}}=544.88$, monoclinic, space group $C_{\mathrm{c}}, Z=4, a=13.168(2), b=13.308(2)$, $c=15.394(2) \AA, \beta=113.608(12)^{\circ}, V=1603.0 \AA^{3}, T=150 \mathrm{~K}$, $F(000)=1128, \quad \mu \quad\left(\mathrm{Mo}-\mathrm{K}_{\alpha}\right)=0.687 \mathrm{~mm}^{-1}, 63109$ reflections measured $\left(R_{\sigma}=0.0440\right), 5633$ unique $\left(R_{\mathrm{int}}=0.0789\right)$, $R=0.0306, w R 2=0.0655, S=1.025, \Delta \rho_{\min }=-0.32 \mathrm{e}^{-3}$,

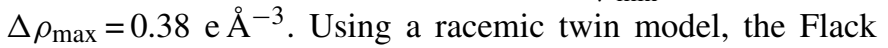
$x$-parameter [19] refined to a value of $0.455(11)$.

\section{Results and discussion}

\subsection{Time-resolved FT-IR experiments}

The kinetics of fatty acid oxidation can be studied using time-resolved FT-IR spectroscopy [20,21], and this method has been shown to be quite useful in the screening of the activity of new potential catalysts [11]. The disappearance of the cis $\mathrm{C}=\mathrm{CH}$ vibration at $3010 \mathrm{~cm}^{-1}$ is especially suitable to follow the disappearance of the substrate in time. In the first step of the radical reaction, a hydrogen is abstracted at the activated methylene group of the cis,cis-1,4-diene moiety and after rearrangement of the resulting radical the cis $\mathrm{C}=\mathrm{CH}$ hydrogen disappears (see Scheme 1). In first approximation, the disappearance of the cis $\mathrm{C}=\mathrm{CH}$ vibration at $3010 \mathrm{~cm}^{-1}$ for $\mathrm{EL}$ is linear in time and can be treated with a pseudo-first-order fit. From the slope of this graph the pseudo-first-order reaction rate of $\mathrm{H}^{\bullet}$ radical abstraction can be determined. The resulting plots as obtained for different catalytic systems are shown in Fig. 1. The graphs have been analyzed and in Table 1 the catalytic activity of different manganese-based catalytic systems is given in terms of induction time and reaction rates.
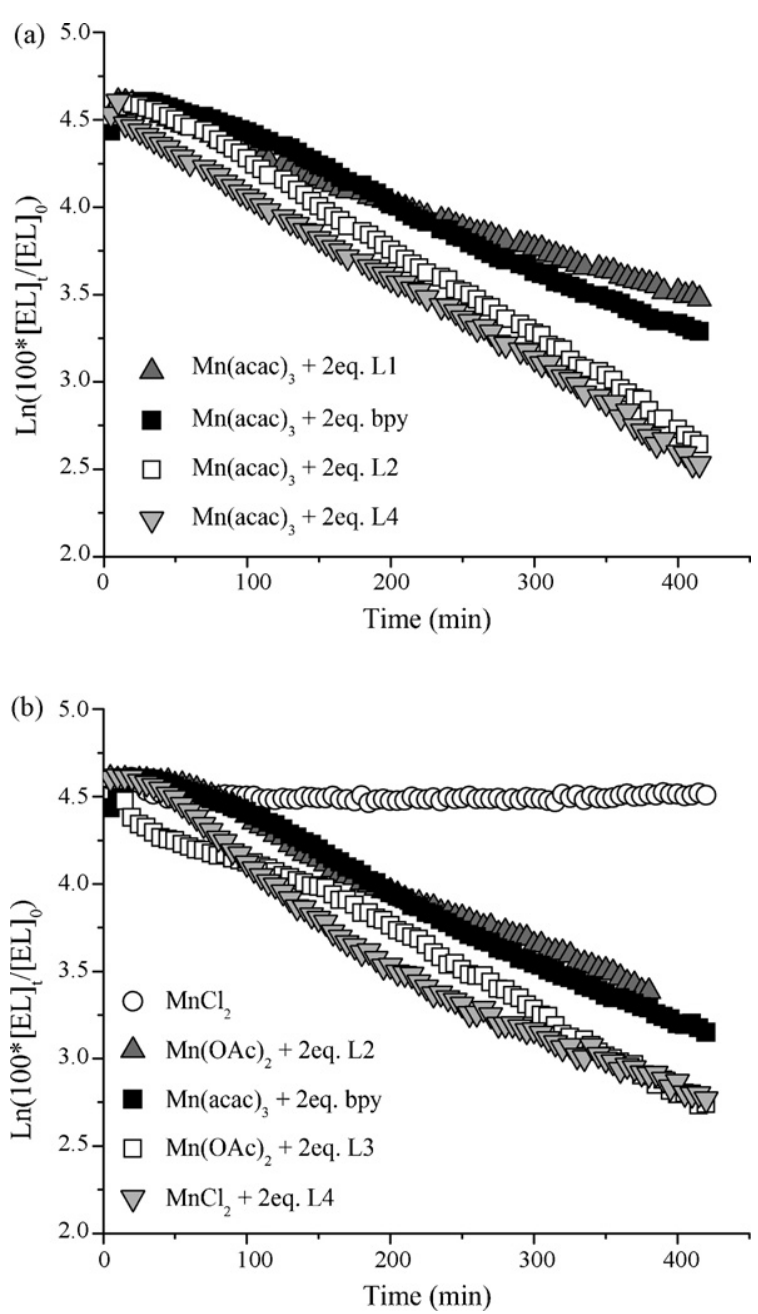

Fig. 1. Time-dependent integral plots of the $3010 \mathrm{~cm}^{-1}$ FT-IR peak of EL, in reactions with different autoxidation catalyst systems. 
Table 1

Catalytic activity of different manganese-based catalytic systems in the autoxidation of $\mathrm{EL}^{\mathrm{a}}$

\begin{tabular}{lcl}
\hline Catalytic systems & Induction time (min) & $\begin{array}{l}\text { Reaction rate }^{\mathrm{b}} \\
\left(\times 10^{-3} \mathrm{~min}^{-1}\right)\end{array}$ \\
\hline $\mathrm{Mn}(\mathrm{acac})_{3}+$ bpy & 50 & 4.2 \\
$\mathrm{Mn}(\mathrm{acac})_{3}+\mathrm{L} 1$ & 30 & 4.0 \\
$\mathrm{Mn}(\mathrm{acac})_{3}+\mathrm{L} 2$ & 20 & 5.3 \\
$\mathrm{Mn}(\mathrm{acac})_{3}+\mathrm{L} 4$ & 10 & 5.4 \\
$\mathrm{Mn}(\mathrm{OAc})_{2}+\mathrm{L} 2$ & 80 & 3.9 \\
$\mathrm{Mn}(\mathrm{OAc})_{2}+\mathrm{L} 3$ & 10 & 4.2 \\
$\mathrm{MnCl}_{2}+\mathrm{L} 4$ & 20 & 5.0 \\
$\mathrm{MnCl}_{2}$ & $>400$ & -
\end{tabular}

${ }^{\text {a }} \mathrm{EL} / \mathrm{Mn} / \mathrm{L} \approx 375 / 1 / 2$. A deviation of $\pm 10 \%$ has been found between different measurements, due to the radical nature of the autoxidation reactions.

b Relative rate calculated from the graph $\left.\ln \left(100[\mathrm{EL}]_{t}\right) /[\mathrm{EL}]_{0}\right)$ vs. time, linear fit of the data after the induction period.

Manganese(II) chloride, manganese(II) acetate and manganese(III) acetylacetonate have been used as sources of manganese ions. Manganese(II) salts without any ligands are ineffective in the autoxidation of EL, as is exemplified by $\mathrm{MnCl}_{2}$, for which even after $400 \mathrm{~min}$ the reaction has not yet started (Fig. 1). Manganese(III) acetylacetonate has been reported to have a shorter induction period (less than $100 \mathrm{~min}$ ) followed by a relatively low rate $\left(1 \times 10^{-3} \mathrm{~min}^{-1}\right)$ [13]. The addition of the Schiff-base ligands L1-L4 to either of the manganese sources leads to significant enhancement of the catalytic activity. In all cases the induction time is reduced (to $20-80 \mathrm{~min}$ ) and the rates of EL consumption after the induction period are 4-5 times higher. Starting either from $\mathrm{MnCl}_{2}$ or $\mathrm{Mn}(\mathrm{acac})_{3}$, the ligand L4 seems to give the best performance; the reaction rate for the combination $\mathrm{MnCl}_{2}$ with two equivalents of the ligand L4 is only slightly lower than that of the combination of $\mathrm{Mn}(\mathrm{acac})_{3}$ with L4. Both catalytic mixtures have improved activities compared to the earlier reported $\mathrm{Mn}(\mathrm{acac})_{3}$ in combination with bipyridine [13], which result is included for comparison.

\subsection{SEC experiments}

The drying and hardening of real alkyd coatings generally depend on the formation of oligomers and cross-links. The oxidation reaction of EL as it is followed by time-resolved FT-IR has to do with the consumption of EL, the abstraction of a hydrogen atom from EL and the formation of a conjugated species. Based on FT-IR no conclusions can be drawn on the formation of oligomers. SEC may be used to obtain a quantitative measure of the hydroperoxide, dimers, and higher oligomers that are formed in the oxidation of EL [12,22]. In Fig. 2 is shown the chromatogram of EL after $8 \mathrm{~h}$ reaction using the catalytic mixture of $\mathrm{MnCl}_{2}$ with two equivalents of the Schiff-base ligand L4. It appears that after a period of $8 \mathrm{~h}$ the formation of dimers and higher oligomers has taken place. The extent of peroxide formation and oligomerisation is comparable to that observed for the catalytic system of $\mathrm{Mn}(\mathrm{acac})_{3}$ with bipyridine [23].

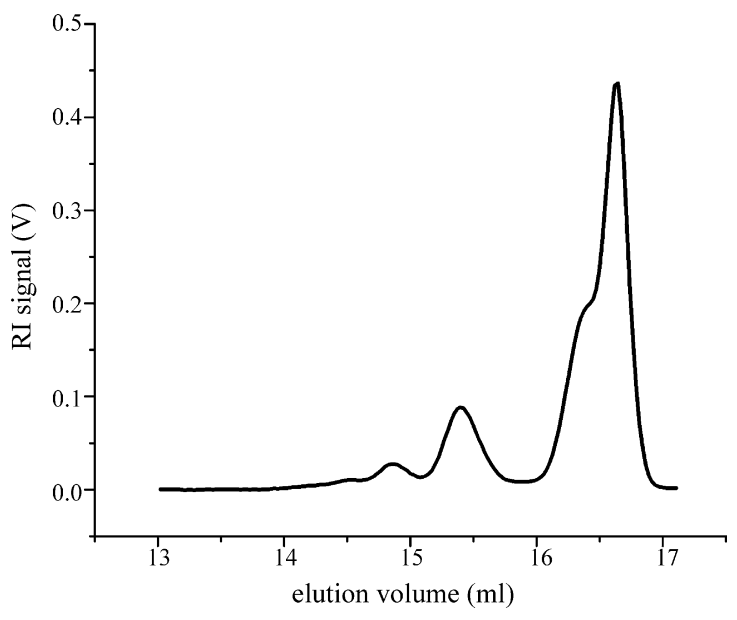

Fig. 2. SEC trace of oligomers obtained from oxidation of EL catalyzed by $\mathrm{MnCl}_{2}+\mathrm{L} 4$ after $8 \mathrm{~h}$.

\subsection{Product of the reaction of $\mathrm{MnCl}_{2}$ with the ligand $L 4$}

Simple manganese(II) chloride appears to be inactive in the autoxidation of EL, however, the catalytic activity increases significantly with the addition of the Schiff-base ligand L4. Therefore, the reaction of $\mathrm{MnCl}_{2} \cdot 2 \mathrm{H}_{2} \mathrm{O}$ with the ligand $\mathrm{L} 4$ has been investigated in more detail. In a methanolic, air-exposed solution the reaction of $\mathrm{MnCl}_{2} \cdot 2 \mathrm{H}_{2} \mathrm{O}$ with the ligand $\mathrm{L} 4$ results in the formation of a red-brown crystalline product. Elemental analysis and single crystal X-ray diffraction methods structurally determined the final compound as $\left[\mathrm{Mn}^{\mathrm{III}}(\mathrm{OL} 4)_{2}\right] \mathrm{Cl} \cdot 3 \mathrm{H}_{2} \mathrm{O}$. An ORTEP projection of the molecular structure of the cationic complex $\left[\mathrm{Mn}^{\mathrm{III}}(\mathrm{OL} 4)_{2}\right]^{+}$is shown in Fig. 3. Selected bond lengths and angles of this complex are given in Table 2.

Two facially coordinating tridentate ligands are bound to the manganese(III) ion, resulting in an $\mathrm{MnN}_{4} \mathrm{O}_{2}$ chromophore

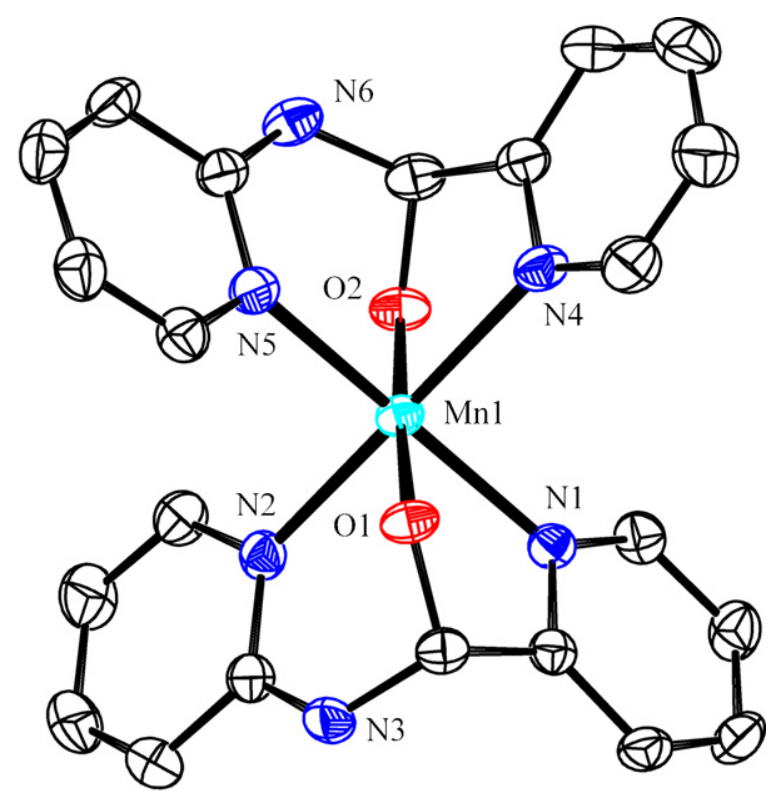

Fig. 3. ORTEP drawing of the cationic complex $\left[\mathrm{Mn}(\mathrm{OL} 4)_{2}\right]^{+}$; thermal ellipsoids are drawn at the $50 \%$ probability level. Hydrogen atoms, the noncoordinating chloride ion and water molecules have been omitted for clarity. 
Table 2

Selected bond distances $[\AA]$ and angles $\left[{ }^{\circ}\right]$ in $\left[\mathrm{Mn}(\mathrm{OL} 4)_{2}\right] \mathrm{Cl} \cdot 3 \mathrm{H}_{2} \mathrm{O}$ (standard uncertainties in parentheses)

\begin{tabular}{lclc}
\hline Mn1-O1 & $1.8596(15)$ & Mn1-O2 & $1.8574(16)$ \\
Mn1-N1 & $2.1464(17)$ & Mn1-N2 & $2.1676(19)$ \\
Mn1-N4 & $2.1859(19)$ & Mn1-N5 & $2.1449(18)$ \\
O1-Mn1-O2 & $176.80(7)$ & O1-Mn1-N1 & $80.51(7)$ \\
O1-Mn1-N2 & $87.66(7)$ & O1-Mn1-N4 & $97.70(7)$ \\
O1-Mn1-N5 & $93.70(7)$ & O2-Mn1-N1 & $97.29(7)$ \\
O2-Mn1-N2 & $94.56(7)$ & O2-Mn1-N4 & $80.01(7)$ \\
O2-Mn1-N5 & $88.38(7)$ & N1-Mn1-N2 & $86.96(7)$ \\
N1-Mn1-N4 & $91.96(7)$ & N1-Mn1-N5 & $173.62(7)$ \\
N2-Mn1-N4 & $174.29(7)$ & N2-Mn1-N5 & $95.52(7)$ \\
N4-Mn1-N5 & $86.14(7)$ & & \\
\hline
\end{tabular}

Table 3

Hydrogen bond geometry $\left[\AA{ }^{\circ}{ }^{\circ}\right]$ in $\left[\mathrm{Mn}(\mathrm{OL} 4)_{2}\right] \mathrm{Cl} \cdot 3 \mathrm{H}_{2} \mathrm{O}$ (standard uncertainties in parentheses) ${ }^{*}$

\begin{tabular}{|c|c|c|c|c|}
\hline & D-H & $\mathrm{H} \cdots \mathrm{A}$ & D $\cdots A$ & $\mathrm{D}-\mathrm{H} \cdots \mathrm{A}$ \\
\hline N3-H3A $\cdots$ O5a & $0.89(3)$ & $1.99(3)$ & $2.875(2)$ & 171(3) \\
\hline $\mathrm{N} 6-\mathrm{H} 6 \mathrm{~A} \cdots \mathrm{Cl} 1 \mathrm{~b}$ & $0.84(3)$ & $2.59(3)$ & $3.361(2)$ & $153(3)$ \\
\hline $\mathrm{O} 3-\mathrm{H} 31 \cdots \mathrm{O} 1$ & $0.90(3)$ & $1.87(3)$ & $2.720(3)$ & $157(2)$ \\
\hline $\mathrm{O} 3-\mathrm{H} 32 \cdots \mathrm{Cl} 1$ & $0.88(3)$ & $2.27(3)$ & $3.087(2)$ & 154(3) \\
\hline $\mathrm{O} 4-\mathrm{H} 41 \cdots \mathrm{O} 2$ & $0.85(3)$ & $1.91(3)$ & $2.758(3)$ & $172(4)$ \\
\hline $\mathrm{O} 4-\mathrm{H} 42 \cdots \mathrm{Cl} 1 \mathrm{c}$ & $0.870(19)$ & $2.309(19)$ & $3.178(2)$ & $176(4)$ \\
\hline $\mathrm{O} 5-\mathrm{H} 51 \cdots \mathrm{Cl} 1 \mathrm{~d}$ & $0.86(2)$ & $2.40(2)$ & $3.2340(19)$ & $163(2)$ \\
\hline $\mathrm{O} 5-\mathrm{H} 52 \cdots \mathrm{O} 4 \mathrm{e}$ & $0.87(2)$ & $1.89(2)$ & $2.709(3)$ & $156(2)$ \\
\hline
\end{tabular}

* Symmetry operations: $a=x, 1-y, 1 / 2+z ; b=-1 / 2+x,-1 / 2+y, z$; $c=-1 / 2+x, 1 / 2-y, 1 / 2+z ; d=-1 / 2+x, 1 / 2-y,-1 / 2+z ; e=1 / 2+x, 1 / 2-y$, $-1 / 2+z$

with an axially-compressed octahedral geometry; the nitrogen donors are all in the equatorial plane with $\mathrm{Mn}-\mathrm{N}$ distances ranging from 2.14-2.19 $\AA$, two anionic oxygen donors occupy the axial positions at $1.86 \AA$. It appears that during the reaction with $\mathrm{MnCl}_{2}$, a molecule of water has added to the imine double bond of the intended Schiff-base ligand $\mathrm{L} 4$ and the tridentate $\mathrm{N}_{2} \mathrm{O}$ donor ligand (2-pyridyl)(2-pyridylamino)methanol (HOL4, see Scheme 3) is formed. The Mn-complex has local two-fold rotation symmetry. This two-fold symmetry is not valid for the crystal packing, as is illustrated by the fact that where $\mathrm{N} 3$ donates a hydrogen bond toward one of the hydrate oxygens (O5), its local-symmetry partner N6 donates a hydrogen bond toward the chloride counter-ion. The crystal packing further displays six unique hydrogen bonds of type hydrate-ligand (involving $\mathrm{O} 1$ and $\mathrm{O} 2$ as acceptors), hydrate-chloride and hydrate-hydrate; geometric details are given in Table 3. These hydrogen bonds link the $\mathrm{Mn}$-complex, $\mathrm{Cl}$ anions and hydrate water molecules into an intricate three-dimensional network. In one complex, the chiral carbon atoms (C6 and C17) have the same hand. Due to the glide-plane symmetry element of the space group both $R, R$ and $S, S$ complexes exist within each unit cell.

Similar structures have been reported for the complexes $\left[\mathrm{Mn}^{\mathrm{III}}(\mathrm{OL} 4)_{2}\right] \mathrm{ClO}_{4}, \quad\left[\mathrm{Fe}^{\mathrm{III}}(\mathrm{OL} 4)_{2}\right] \mathrm{ClO}_{4}$ and $\left[\mathrm{Co}^{\mathrm{III}}(\mathrm{OL} 4)_{2}\right]$ $\mathrm{ClO}_{4}$, which were supposedly formed by metal-assisted decomposition of the aminal ligand (2-pyridyl)bis(2-pyridylamino) methane (L4b in Scheme 3) [24,25]. These findings triggered the reinvestigation of the true nature of the Schiff-base ligands used in this study.

\subsection{Reinvestigation of the Schiff-base ligands and their complexes}

The manganese complex $\left[\mathrm{Mn}(\mathrm{OL} 4)_{2}\right] \mathrm{Cl} \cdot 3 \mathrm{H}_{2} \mathrm{O}$ was obtained from a solution containing an equimolar mixture of 2-pyridinecarboxaldehyde and 2-pyridineamine. Careful reexamination of this ligand solution with ESI-MS revealed that the solution used in the studies described above in fact contained both the expected Schiff-base ligand L4 $(\mathrm{m} / \mathrm{z}=183.99)$ and the reported aminal ligand L4b $(m / z=279.03)$. After partial evaporation of the solvent a colorless, highly crystalline material is obtained. NMR spectroscopy shows that this crystalline product is also a mixture of both the Schiff-base L4 and the aminal ligand L4b, as reflected by the presence of a resonance for the imine $\mathrm{CH}$ at $9.1 \mathrm{ppm}$ as well as the tertiary $\mathrm{CH}$ at $6.2 \mathrm{ppm}$, together with a complex pattern of multiple resonances for the pyridyl protons. Only after heating the crystalline material in vacuo for several hours at $120^{\circ} \mathrm{C}$, the addition of the second molecule of 2-pyridineamine is reversed - the pyridineamine is irreversibly removed by evaporation - and pure Schiff-base ligand L4 can be obtained [26]. As the catalytic oxidation of EL requires the involvement of both $\mathrm{Mn}^{\mathrm{III}}$ and $\mathrm{Mn}^{\mathrm{II}}$, the reaction of manganese(II) chloride with the solution containing the ligand mixture has also been investigated with vigorous exclusion of dioxygen; a colorless/pale yellow complex could be obtained. The analytical characterizations indicate that the ligand is present as the Schiff-base in a complex that can be formulated as $\mathrm{Mn}^{\mathrm{II}}(\mathrm{L} 4) \mathrm{Cl}_{2}(\mathrm{MeOH})$.

The unexpected results with the ligand L4 prompted the careful characterization of the solutions supposedly containing the Schiff-base ligands L1-L3. Although coordination complexes of the ligands L1 [27,28] and L2 [29] have been reported, these ligands mostly have been prepared and used in situ and have not been characterized with NMR. Reexamination of the ligand solutions used in our studies with ESI-MS and NMR has shown that a 1:1 mixture of 2-

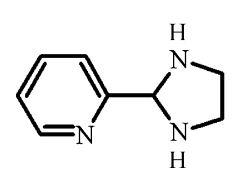

$\mathrm{L} 1 \mathrm{~b}$

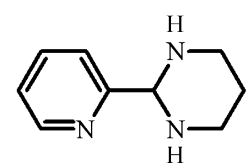

L2b

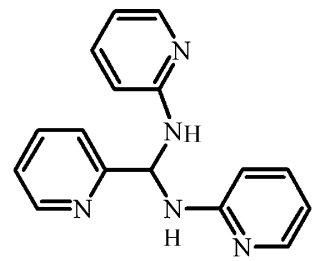

$\mathrm{L} 4 \mathrm{~b}$

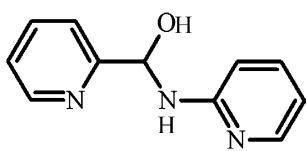

HOL4

Scheme 3. Alternative structures of the ligands present in the in situ mixtures in solution. 
pyridinecarboxaldehyde and 1,2-diaminoethane results in a complex mixture containing the desired Schiff-base (L1), the ring-closed product 2-(imidazolidin-2-yl)pyridine (L1b) and possibly the 2:1 product $N, N^{\prime}$-bis(2-pyridylmethylene)1,2-diaminoethane. NMR characterization of a solution containing a 1:1 mixture of 2-pyridinecarboxaldehyde and 1,3-diaminopropane indicates that in solution mainly the ringclosed product 2-(hexahydropyrimidin-2-yl)pyridine (L2b) is formed; additionally ESI-MS shows the presence of traces of the $2: 1$ condensation product $N, N^{\prime}$-bis(2-pyridylmethylene)-1,3diaminopropane (L3). Analysis of a solution containing a 2:1 mixture of 2-pyridinecarboxaldehyde and 1,3-diaminopropane confirms that in this case the expected ligand L3 is the sole reaction product.

\subsection{Implications of ligand structures for paint-drying catalysis}

As shown by the reaction sequence given in Scheme 1, the hydroperoxide decomposition and the formation of radical species determine the rate of the catalytic reaction. Regarding the high reaction rates as given in Table 1, the ligands used in this study apparently are suitable for the stabilization of both the manganese(II) and the manganese(III) oxidation states necessary for the Haber-Weiss decomposition of the alkyl hydroperoxides that are generated in the process. For the earlier reported system $\mathrm{Mn}(\mathrm{acac})_{3}$ /bipyridine it was suggested that this catalytic system is capable even of starting the radical process by $\mathrm{H}$ atom abstraction of the fatty acid side chain [13]. The very short induction times observed for the new manganese/ligand combinations described in this manuscript suggest that also in this case radical initiation may be an important part of the activity of the catalysts.

Despite the fact that the ligands L1 and L2 in solution are not present as such, upon the addition of a metal ion due to the chelating effect the "open" tridentate ligands are predominant, as is confirmed by the complexation studies reported earlier [27-29]. The ligand L3 is present in solution as such, and it has been reported as a ligand for iron complexes used in oxidation catalysis [30]. Only for the ligand L4 the situation in solution appears to be more complex than anticipated. However, the various ligand structures that may be present in these solutions are capable of stabilizing both $\mathrm{Mn}^{\mathrm{II}}$ and $\mathrm{Mn}^{\mathrm{III}}$, thus rationalizing the high activity of this particular system.

\section{Conclusions}

Simple manganese salts in combination with Schiff-base ligands are efficient catalysts for the oxidation and the oligomerisation of EL, as was shown by the use of time-resolved FT-IR spectroscopy and size-exclusion chromatography. The results of time-resolved FT-IR indicated that the new catalyst systems possess a relatively high activity for the autoxidation of EL, not only by catalyzing the peroxide decomposition, but possibly also by assisting the radical initiation. The catalytic system obtained with the ligand L4 was studied in detail. It was found that the supposed Schiff-base ligand L4 in solution in fact is a complex mixture of products, which in the presence of high-valent metal ions react with water with the formation of another tridentate ligand (HOL4). With this hydrated ligand the manganese(III) complex $\left[\mathrm{Mn}^{\mathrm{III}}(\mathrm{OL} 4)_{2}\right] \mathrm{Cl} \cdot 3 \mathrm{H}_{2} \mathrm{O}$ can be synthesized, whereas manganese(II) ions form the complex $\left[\mathrm{Mn}^{\mathrm{II}}(\mathrm{L} 4) \mathrm{Cl}_{2}(\mathrm{MeOH})\right]$. In situ formation of these two species may play a role in the observed high activity in the autoxidation of EL.

The readily obtained ligands that are formed by simple in situ mixing of 2-pyridinecarboxaldehyde and amines and the high catalytic activity that is observed with simple manganese salts in the oxidation of EL make these systems promising candidates for possible application in actual paint formulations.

\section{Supplementary material}

Crystallographic data (excluding structure factors) for the structural analysis have been deposited with the Cambridge Crystallographic Data Centre, CCDC 643501. Copies of this information may be obtained free of charge from The Director, CCDC, 12 Union Road, Cambridge, CB2 1EZ, UK (fax: +44 1223336 033; email: deposit@ccdc.cam.ac.uk or www: http://www.ccdc.cam.ac.uk).

\section{Acknowledgements}

We are grateful to Dr. S. Tanase for her continuing interest in this study and her help in the reproduction of some of the data. We thank Prof. J. Reedijk for stimulating discussions. We are indebted to Mr. J.A.P.P. van Dijk for assistance with the SEC measurements and to Mrs. J.A. Erkelens-Duijndam for assistance with the MS measurements. This work was supported in part (ALS) by the Council for the Chemical Sciences of the Netherlands Organization for Scientific Research (CW-NWO).

\section{References}

[1] R. van Gorkum, E. Bouwman, Coord. Chem. Rev. 249 (2005) 1709.

[2] Z.O. Oyman, W. Ming, F. Micciche, E. Oostveen, J. van Haveren, R. van der Linde, Polymer 45 (2004) 7431.

[3] S.J. Tuman, D. Chamberlain, K.M. Scholsky, M.D. Soucek, Prog. Org. Coat. 28 (1996) 251.

[4] W.J. Muizebelt, J.C. Hubert, R.A.M. Venderbosch, Prog. Org. Coat. 24 (1994) 263.

[5] R.A. Hancock, N.J. Leeves, P.F. Nicks, Prog. Org. Coat. 17 (1989) 321.

[6] N.A. Porter, S.E. Caldwell, K.A. Mills, Lipids 30 (1995) 277.

[7] J.H. Bieleman, Additives for Coatings, Wiley VCH, Weinheim, 2000.

[8] R.A. Sheldon, J.K. Kochi, in: D.D. Eley, H. Pines, P. Weisz (Eds.), Advances in Catalysis, vol. 25, Academic Press, New York, 1976, p. 274.

[9] J.R. Bucher, J.R. Hailey, J.R. Roycroft, J.K. Haseman, R.C. Sills, S.L. Grumbein, P.W. Mellick, B.J. Chou, Toxicol. Sci. 49 (1999) 56.

[10] D. Lison, M. De Boeck, V. Verougstraete, M. Kirsch-Volders, Occup. Environ. Med. 58 (2001) 619.

[11] S.T. Warzeska, M. Zonneveld, R. van Gorkum, W.J. Muizebelt, E. Bouwman, J. Reedijk, Prog. Org. Coat. 44 (2002) 243.

[12] J.Z. Wu, E. Bouwman, J. Reedijk, Prog. Org. Coat. 49 (2004) 103

[13] R. van Gorkum, E. Bouwman, J. Reedijk, Inorg. Chem. 43 (2004) 2456.

[14] F. Micciche, E. Oostveen, J. van Haveren, R. van der Linde, Prog. Org. Coat. 53 (2005) 99.

[15] F.R. Vandevoort, A.A. Ismail, J. Sedman, G. Emo, J. Am. Oil Chem. Soc. 71 (1994) 243. 
[16] G.M. Sheldrick, SHELXLS-86: Program for Crystal Structure Determination, University of Göttingen, Göttingen (Germany), 1986.

[17] G.M. Sheldrick, SHELXL-97: Program for Crystal Structure Refinement, University of Göttingen, Göttingen (Germany), 1997.

[18] A.L. Spek, J. Appl. Crystallogr. 36 (2003) 7.

[19] H.D. Flack, Acta Cryst. A39 (1983) 876.

[20] N.A.R. Falla, J. Coat. Technol. 64 (1992) 55.

[21] J.H. Hartshorn, J. Coat. Technol. 54 (1982) 53.

[22] J. Mallegol, J. Lemaire, J.L. Gardette, Prog. Org. Coat. 39 (2000) 107.

[23] Z.O. Oyman, W. Ming, R. van der Linde, R. van Gorkum, E. Bouwman, Polymer 46 (2005) 1731.

[24] N. Arulsamy, D.J. Hodgson, Inorg. Chem. 33 (1994) 4531.
[25] H. Adams, M.S. Shongwe, I. Al-Bahri, E. Al-Busaidi, M.J. Morris, Acta Crystallogr. Sect. C: Cryst. Struct. Commun. 61 (2005) M497.

[26] I. Iovel, L. Golomba, J. Popelis, S. Grinberga, S. Belyakov, E. Lukevics, Chem. Heterocyclic Comp. 38 (2002) 1210.

[27] S. Banerjee, J. Gangopadhyay, C.Z. Lu, J.T. Chen, A. Ghosh, Eur. J. Inorg. Chem. (2004) 2533.

[28] P. Krumholz, Inorg. Chem. 4 (1965) 612.

[29] S. Chattopadhyay, M.S. Ray, M.G.B. Drew, A. Figuerola, C. Diaz, A. Ghosh, Polyhedron 25 (2006) 2241.

[30] M. Klopstra, R. Hage, R.M. Kellogg, B.L. Feringa, Tetrahedron Lett. 44 (2003) 4581. 